\title{
Beverage purchases from stores in Mexico under the excise tax on sugar sweetened beverages: observational study
}

\author{
M Arantxa Colchero, ${ }^{1}$ Barry M Popkin, ${ }^{2}$ Juan A Rivera, ${ }^{3}$ Shu Wen Ng²
}

${ }^{1}$ Center for Health Systems

Research, Instituto Nacional de

Salud Pública, Universidad No

655 Colonia Santa María

Ahuacatitlán, Cuernavaca,

Morelos, Mexico

${ }^{2}$ Department of Nutrition and

Carolina Population Center,

University of North Carolina at

Chapel Hill, Chapel Hill, NC

27516, USA

${ }^{3}$ Nutrition and Health Research

Center, Instituto Nacional de

Salud Pública, Mexico

Correspondence to: S W Ng

shuwen@unc.edu

Additional material is published online only. To view please visit the journal online (http://dx.doi. org/10.1136/bmj.h6704)

Cite this as: BMJ 2016;352:h6704 http://dx.doi.org/10.1136/bmj.h6704 Accepted: 24 November 2015

\section{ABSTRACT}

\section{STUDY QUESTION}

What has been the effect on purchases of beverages from stores in Mexico one year after implementation of the excise tax on sugar sweetened beverages?

METHODS

In this observational study the authors used data on the purchase of beverages in Mexico from January 2012 to December 2014 from an unbalanced panel of 6253 households providing 205112 observations in 53 cities with more than 50000 inhabitants. To test whether the post-tax trend in purchases was significantly different from the pretax trend, the authors used a difference in difference fixed effects model, which adjusts for both macroeconomic variables that can affect the purchase of beverages over time, and pre-existing trends. The variables used in the analysis included demographic information on household composition (age and sex of household members) and socioeconomic status (low, middle, and high). The authors compared the predicted volumes ( $\mathrm{mL} /$ capita/day) of taxed and untaxed beverages purchased in 2014-the observed post-tax period-with the estimated volumes that would have been purchased if the tax had not been implemented (counterfactual) based on pretax trends.

\section{STUDY ANSWER AND LIMITATIONS}

Relative to the counterfactual in 2014, purchases of taxed beverages decreased by an average of $6 \%(-12$ $\mathrm{mL} /$ capita/day), and decreased at an increasing rate up to a $12 \%$ decline by December 2014 . All three socioeconomic groups reduced purchases of taxed beverages, but reductions were higher among the households of low socioeconomic status, averaging a $9 \%$ decline during 2014 , and up to a $17 \%$ decrease by December 2014 compared with pretax trends. Purchases of untaxed beverages were $4 \%(36 \mathrm{~mL} /$ capita/day) higher than the counterfactual, mainly driven by an increase in purchases of bottled plain water.

\section{WHAT IS ALREADY KNOW ON THIS TOPIC}

Mexico has one of the highest prevalence rates for diabetes, overweight, and obesity in the world

Reducing the consumption of sugar sweetened beverages has been an important target for obesity and diabetes prevention efforts

Mexico implemented an excise tax of 1 peso/L on sugar sweetened beverages from 1 January 2014

\section{WHAT THIS STUDY ADDS}

During the first year of the tax, the average volume of taxed beverages purchased monthly was $6 \%$ lower in 2014 than would have been expected without the tax The reduction was greatest among the households of the lowest socioeconomic status

\section{WHAT THIS STUDY ADDS}

The tax on sugar sweetened beverages was associated with reductions in purchases of taxed beverages and increases in purchases of untaxed beverages. Continued monitoring is needed to understand purchases longer term, potential substitutions, and health implications.

FUNDING, COMPETING INTERESTS, DATA SHARING This work was supported by grants from Bloomberg Philanthropies and the Robert Wood Johnson Foundation and by the Instituto Nacional de Salud Pública and the Carolina Population Center. The authors have no competing interests. No additional data are available.

\section{Introduction}

Myriad studies suggest that added sugar in beverages is linked with obesity and many cardiometabolic problems and have recommended that efforts to reduce consumption of sugar sweetened beverages to obtain meaningful improvement to health would require a tax that leads to price increases. ${ }^{1-7}$ Aside from industry funded studies, the consensus from a large literature of randomized controlled trials, ${ }^{8}$ longitudinal cohort studies, and smaller clinical studies is that humans do not reduce food intake when consuming caloric beverages. The lack of dietary compensation is hypothesized to be due to form (liquid versus solid), beverage type (for example, carbohydrate content, fat content), and resultant release of hormones such as ghrelin and insulin. ${ }^{9}$ Therefore, reducing the intake of sugar sweetened beverages could reduce body weight and many cardiometabolic problems. ${ }^{510-12}$

The likelihood of obesity among Mexicans of all ages is high. ${ }^{1314}$ The prevalence of overweight and obesity is more than 33\% for young people aged 2-18 years (about the same across all age groups) and around $70 \%$ for adults (half of whom are obese). ${ }^{15-17}$ The prevalence of diabetes in Mexico (based on hospital admissions) is the highest among the Organization for Economic Cooperation and Development countries, ${ }^{18}$ and ischemic heart disease and diabetes are the two leading causes of mortality in Mexico. ${ }^{19}$ Additionally, the prevalence of overweight and obesity increased by $12 \%$ between 2000 and 2006 and reached 72\% among adults in 2012. ${ }^{14}$ Concomitant with the rise in obesity and diabetes in Mexico are large increases in the consumption of sugar sweetened beverages ${ }^{20} 21$-Mexico had the largest per capita (163 liters) intake of soft drinks in 2011. Several studies showed that before the debate over this tax the intake of sugar sweetened beverages was rapidly increasing in Mexico. ${ }^{20-22}$ Reducing such consumption has been an important target for obesity and diabetes prevention. ${ }^{2324}$ A Ministry of 
Health beverage guidance panel had proposed a tax years earlier and it was endorsed, among others, by many medical societies. ${ }^{24}$

In September 2013, as part of the federal budget, the Mexican congress passed an excise tax on sugar sweetened beverages and a sales tax on several highly energy dense foods. ${ }^{25}$ A specific excise tax of 1 peso/L (approximately a 10\% price increase based on 2013 prices) on non-dairy and non-alcoholic beverages with added sugar and an ad valorem tax of $8 \%$ on a defined list of non-essential highly energy dense foods (containing $\geq 275$ calories (1151 kJ) per $100 \mathrm{~g}$ ) came into effect on 1 January 2014. Agencies collect the excise tax on sugar sweetened beverages from the manufacturers, and other research indicates that this tax is entirely passed on to consumers at the point of sale. Prices of sugar sweetened beverages increased on average by 1 peso/L in 2014 (exactly the amount of the tax), and these changes in prices, which began in the tax's first month, were observed throughout the year. ${ }^{2627}$ Using scanned and recorded food purchase data from a representative group of Mexican households in cities with more than 50000 residents from January 2012 through December 2014, we evaluated changes in the purchases of consumer beverages after the implementation of the excise tax.

\section{Methods}

We obtained data on purchases from January 2012 through December 2014 from Nielsen Mexico’s Consumer Panel Services, which is equivalent to the data from the US Nielsen Homescan panel. ${ }^{28}$ In the US, Nielsen Homescan data have been used in several studies, including some that have linked purchases to data on nutrition labels to determine the caloric content of purchases and to evaluate industry efforts. ${ }^{29} 30$ However, linking purchases to nutrition data is currently not possible in Mexico owing to the lack of comprehensive data sources related to labeling. Therefore we focused on changes in the volumes of beverages purchased.

Each year the Nielsen Mexico Consumer Panel Services samples Mexican households in 53 cities (in 28 states plus Mexico City) with more than 50000 inhabitants. Based on government statistics, this sample represents $63 \%$ of the Mexican population and $75 \%$ of food and beverage expenditures in 2014. ${ }^{31}$ The original dataset contained 205827 household-month observations from 6286 households. We used complete case analysis; 715 observations $(0.3 \%)$ were dropped because of missing information on the highest educational attainment of the heads of the households. Consequently, our analytic sample included 205112 household months across 6253 households, of which $86 \%$ participated in all rounds. Each household is weighted based on household composition, locality, and socioeconomic measures through iterative proportional fitting to match demographic estimates from the National Institute of Statistics and Geography (Instituto Nacional de Estadística Geografía e Informática, INEGI). Enumerators visited the households every two weeks to collect diaries, product packaging from special bins provided for this study (scanned by the enumerators), and receipts, and to carry out pantry surveys. Bar code information provided all other data.

For descriptive purposes, we categorized the sample into the six regions used by INEGI: central north, central south, Mexico City, north east, north west, and south. The variables we used in the analysis included demographic information on household composition (age and sex of each household member) and socioeconomic status; information that is updated annually. Socioeconomic status groups (low, middle, and high) were based on a six category measure derived from annually updated questions on household ownership of assets (for example, number of bathrooms, number of bedrooms, number of vehicles owned) and education attainment of the head of the household. Onto the Nielsen Mexico Consumer Panel Services data we overlaid two contextual measures: the state's quarterly unemployment rate from INEGI, ${ }^{32}$ and the two economic minimum daily salary for each year from Mexico's National Commission of Minimum Salaries ${ }^{33}$ (after adjusting for state and quarter specific inflation from INEGI's consumer price indices, www.inegi.org.mx/est/ contenidos/proyectos/inp/inpc.aspx).

In this analysis we used the purchase of beverages by each household between 1 January 2012 and 31 December 2014. Data from the Nielsen Mexico Consumer Panel Services include the number of units purchased and the volume and price of each unit. From these we totalled the monthly volume and beverage categories each household purchased across each of the 36 months. Then we calculated the volume per capita per day for interpretability. Our beverage categories followed the 2012 National Health and Nutrition Survey (Encuesta Nacional de Salud y Nutrición) groupings for beverage intake as much as possible; ${ }^{2234}$ these were further grouped into larger categories or subgrouped as described in supplemental table 1 . We classified products into beverage categories in 2014 based on product descriptions and sources available on the internet and in stores. In this study we focus on the top level taxed and untaxed beverages. Our two categories for taxed beverages were carbonated sodas and non-carbonated sugar sweetened beverages, and our three categories for untaxed beverages were carbonated drinks such as diet sodas; sparkling, still, or plain water; and other drinks, including unsweetened dairy beverages and fruit juices. The Consumer Panel Services did not collect information on purchases of dairy products from all of the sampled households until October 2012 (personal communication). Therefore we limited our analyses of the categories "other untaxed drinks" and "overall untaxed beverages" to October 2012 through December 2014.

\section{Patient involvement}

No patients were involved in setting the research question or outcome measures, nor were they involved in the design and implementation of the study. There are no plans to involve patients in the dissemination of results. 


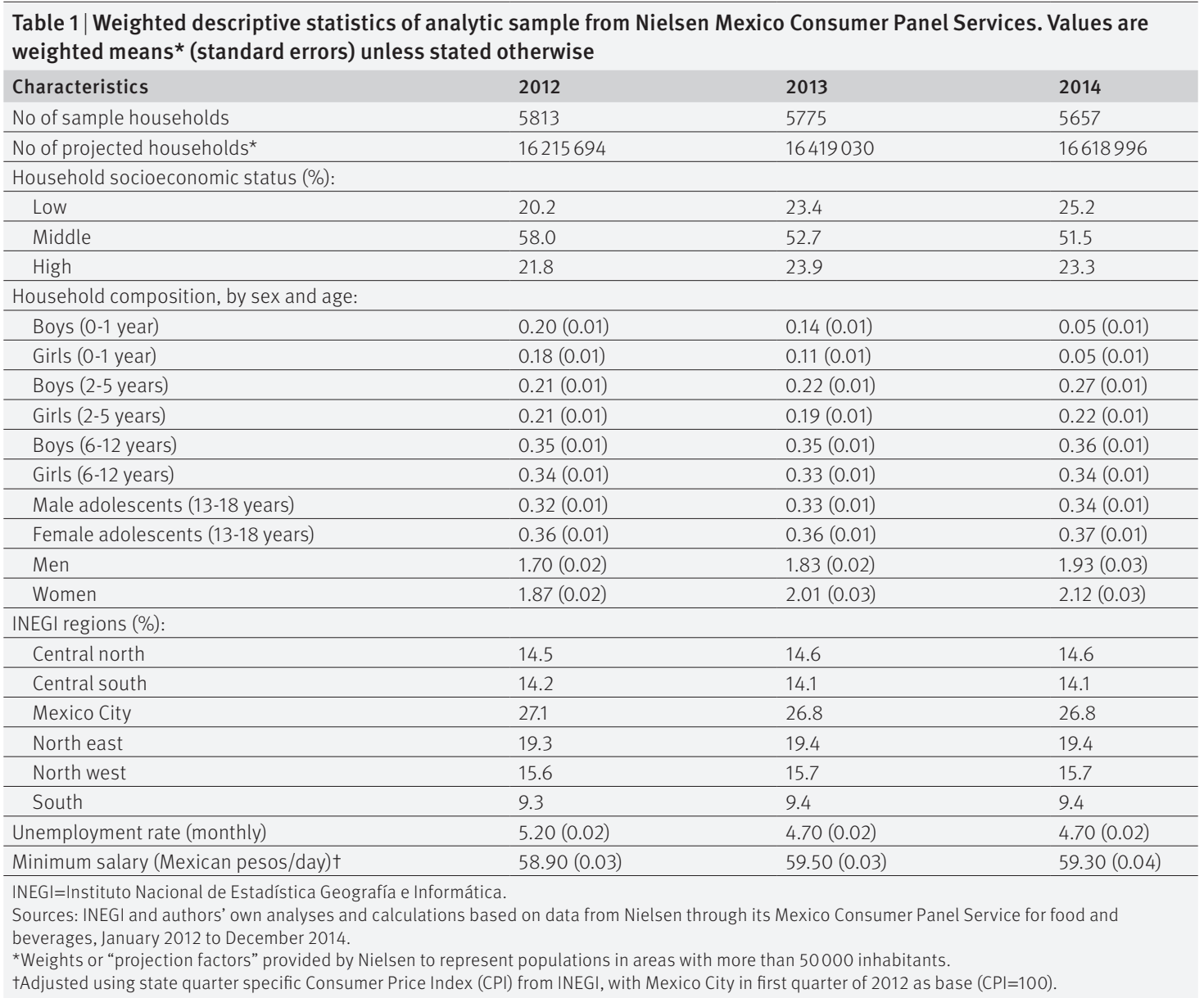

\section{Descriptive statistics}

We present descriptive statistics of the households in the analytic data. Then we present the unadjusted trends in household purchases as reported during the period January 2012 through December 2014, which includes the first year of the post-tax period (beginning 1 January 2014). We conducted simple $t$ tests to determine whether the volume of beverages purchased in each post-tax month was statistically different from that of the same month in 2012 and 2013. Stata 13 was used for all analyses. ${ }^{35}$

\section{Difference in difference fixed effects analyses}

As the tax was implemented nationally, it was not possible to construct a true experimental design to study the association between the tax on sugar sweetened beverages and purchases. Therefore we applied a prepost quasiexperimental approach using difference in difference analyses along with fixed effects models, ${ }^{3637}$ with fixed effects at the household level. Fixed effect models have several advantages, mainly that they account for non-time varying unobserved characteristics of households (for example, preference for certain types of beverages). As such, non-time varying measures (for example, region of household's residence) are omitted in the model.

As the distribution of beverage purchases per capita were skewed and not normally distributed, we used the logarithm of beverage purchases as outcomes in the models. The model adjusts for the seasonality of beverage purchases using a variable for each quarter of the year and demographic information on household composition, socioeconomic status, and contextual factors (unemployment rate and minimum salary).

To allow for interpretability, we back transformed the logged outcomes into milliliters per capita by calculating and applying Duan smearing factors..$^{38}$ Specifically, Duan smearing ensures that in the presence of non-zero variances in the volume purchased, the back transformed predicted outcome is not downward biased. ${ }^{38}$ This also allowed us to compare in absolute and relative terms the estimated post-tax volume of beverages purchased in January through December 2014 to the estimated counterfactual post-tax volume assuming a pretax trend. We did consider presenting predicted values that also detrended seasonality, by setting all quarters to the same quarter, but these seasonal trends are interesting and more accurately reflect the changing demand for beverages over the course of the year. We also corrected the standard errors by clustering the analyses at household level.

The model also takes into consideration periods of non-purchases of beverage categories, when more than $10 \%$ of the observations using inverse probability weights were non-purchases. We calculated inverse probability weights by modeling the probability of 
purchasing, adjusted for the same covariates as the main regression for the log of purchases (the inverse of the predicted values obtained from this model being used in the main regression as a weighting factor). ${ }^{3940}$ We conducted analyses for the full sample and stratified the analyses by socioeconomic status (low, middle, high), using separate models to determine if there were differences for these subsamples. The supplemental materials provide additional details on the analytic approach. We used Stata 13 for all analyses. ${ }^{35}$

\section{Sensitivity analysis among untaxed beverages}

We conducted sensitivity analysis for the untaxed beverages modeled from October 2012 to December 2014. Given the large number of missing values for dairy beverages from January to September 2012, imputation was not an adequate option. Instead, we repeated the models excluding dairy beverages and compared the results from January 2012 to December 2014 with those from October 2012 to December 2014.

\section{Results}

Descriptive trends in household purchases

Table 1 presents the unadjusted characteristics of the households for each year. This analytic sample of reported purchases represents more than 16 million households (approximately 90-100 million residents) in Mexico in each of these years.

Before controlling for any potential factors, strong seasonal effects on beverage purchases need to be considered. In Mexico, seasonality can be due to changes in temperature (though these temperature changes are not extreme in Mexico), holidays and festivities, and fewer purchases at the beginning of the year after the festivities in December (see supplemental fig 1). There is also a decrease in overall purchases of taxed beverages (see supplemental fig 1a), particularly in 2014. We are only able to present unadjusted purchases since October 2012 for untaxed beverages (see supplemental fig 1b), and there is an absolute increase in the volume purchased over time.

\section{Model predicted differences in beverage purchases in stores: overall findings}

Supplemental table 2 presents the coefficient estimates for each of the beverage categories from the difference in difference fixed effects models at the household level controlling for socioeconomic status, age, and sex, and for contextual measures of households. Based on these estimates, we back transformed the predicted log volumes for each of the 12 post-tax months using Duan smearing. ${ }^{38}$ We compared estimated counterfactual volumes purchased in the post-tax period based on pretax trends (expected volumes if the tax had not been implemented) to adjusted volumes purchased in the post-tax period (based on predicted values from the model) and derived the absolute and relative differences from January to December 2014.

Table 2 and figure 1 show that for taxed beverages the absolute and relative differences between the post-tax volume and its counterfactual widened over the 12 post- tax months from $-11 \mathrm{~mL} /$ capita/day $(-5.6 \%$ relative to the counterfactual) in June to $-22 \mathrm{~mL} /$ capita/day $(-12 \%$ relative to the counterfactual) by December 2014, giving an average change of $-6.1 \%$ over 2014. In total, during 2014 the average urban Mexican purchased $4241 \mathrm{~mL}$ (seven $600 \mathrm{~mL}$ or $20 \mathrm{oz}$ bottles) fewer taxed beverages than expected (based on pretax trends). This was related to a decrease in purchases of non-carbonated sugar sweetened beverages $(-17 \%$ relative to the counterfactual) and taxed sodas $(-1.2 \%$ relative to the counterfactual). See supplemental Figure 2.

For untaxed beverages the absolute (and relative) differences were initially higher, at $63 \mathrm{~mL} /$ capita/day (7.5\% relative to the counterfactual) in January 2014, and though the difference remained positive, it decreased over the 12 month post-tax period and was no longer statistically different from the counterfactual by November 2014. None the less, this represents an average increase in the purchase of untaxed beverages, of $36 \mathrm{~mL} / \mathrm{capita} /$ day (4\% relative to the counterfactual), which translates to the purchase of $12827 \mathrm{~mL}$ (21600 $\mathrm{mL}$ or $20 \mathrm{oz}$ bottles) more untaxed beverages by the average urban Mexican over 2014 than expected.

Sensitivity analyses among the untaxed beverages showed that the model appears sensitive to the pretax period used. Limiting the analyses to untaxed beverages excluding dairy beverages, we found a relative increase in purchases by 2\% when using January 2012 to December 2013 as the pretax period. This was 5\% when using October 2012 to December 2013 as the pretax period. These results suggest that the estimated $4 \%$ for all untaxed beverages may be an overestimate, but positive (relative increase) none the less. Given the nature of incomplete data on beverages from the diaries, we are unable to provide an estimate on the magnitude of the overestimation without making major assumptions, but to provide context, dairy beverages represent $17 \%$ of the untaxed beverages since October 2012.

\section{Difference in store purchases after the tax by household socioeconomic status}

Supplemental table 3 provides the coefficient estimates for each of the beverage categories from the difference in difference fixed effects models stratified by socioeconomic status. Based on these estimates, we back transformed the predicted log volumes for each of the 12 post-tax months using Duan smearing. Supplemental table 4 presents the absolute and relative differences in the estimated counterfactual volumes that would have been purchased in the post-tax period based on pretax trends (expected volumes if the tax had not been implemented) and the predicted volumes purchased in the post-tax period by the three socioeconomic status levels. Figures 2 and 3 present the results for taxed and untaxed beverages, respectively. Both figures show clear seasonal trends in the purchases of taxed and untaxed beverages, with higher purchases in April to September of each year.

Purchases of taxed beverages were already declining during the pretax period across all three socioeconomic 


\begin{tabular}{|c|c|c|c|c|c|}
\hline \multirow[b]{2}{*}{ Post-tax months (2014) } & \multicolumn{3}{|l|}{ Mean (SE) } & \multicolumn{2}{|l|}{ Difference } \\
\hline & $\begin{array}{l}\text { Estimated adjusted counterfactual } \\
\text { (expected volume purchased based } \\
\text { on pretax trends) }\end{array}$ & $\begin{array}{l}\text { Estim } \\
\text { volum }\end{array}$ & $\begin{array}{l}\text { sted post-tax } \\
\text { sed }\end{array}$ & $\begin{array}{l}\text { Absolute difference(post- } \\
\text { tax volume purchased } \\
\text { minus counterfactual } \\
\text { volume) }\end{array}$ & $\begin{array}{l}\text { Relative difference (absolute } \\
\text { difference as } \% \text { of counterfactual, } \\
100 \% \times \text { absolute difference/ } \\
\text { adjusted counterfactual volume) }\end{array}$ \\
\hline \multicolumn{6}{|l|}{ Taxed beverages } \\
\hline Jan & 0.37 & 182 & 0.37 & 0 & 0.0 \\
\hline Feb & 0.36 & 179 & 0.36 & -2 & -1.2 \\
\hline Mar & 0.36 & 176 & 0.35 & $-4^{\star \star}$ & -2.3 \\
\hline Apr & 0.41 & 195 & 0.40 & $-7^{\star \star}$ & -3.4 \\
\hline May & 0.41 & 192 & 0.39 & $-9^{\star \star}$ & -4.5 \\
\hline Jun & 0.41 & 188 & 0.38 & $-11^{\star \star}$ & -5.6 \\
\hline Jul & 0.41 & 187 & 0.38 & $-13^{\star \star}$ & -6.7 \\
\hline Aug & 0.40 & 183 & 0.37 & $-15^{\star \star}$ & -7.8 \\
\hline Sep & 0.40 & 180 & 0.37 & $-17^{\star \star}$ & -8.8 \\
\hline Oct & 0.38 & 170 & 0.34 & $-19^{\star \star}$ & -9.9 \\
\hline Nov & 0.38 & 166 & 0.34 & $-20^{\star *}$ & -10.9 \\
\hline Dec & 0.38 & 163 & 0.33 & $-22^{\star \star}$ & -11.9 \\
\hline Average over 2014 & 192 & 180 & - & $-12^{\star \star}$ & -6.1 \\
\hline \multicolumn{6}{|l|}{ Untaxed beverages } \\
\hline Jan & 1.88 & 908 & 2.02 & $63^{\star \star}$ & 7.5 \\
\hline Feb & 842 & 899 & 2.00 & $58^{\star \star}$ & 6.8 \\
\hline Mar & 1.86 & 890 & 1.98 & $52^{\star \star}$ & 6.2 \\
\hline Apr & 1005 & 1060 & 2.40 & $56^{\star \star}$ & 5.5 \\
\hline May & 1001 & 1050 & 2.38 & $49^{\star \star}$ & 4.9 \\
\hline Jun & 2.26 & 1040 & 2.36 & $42^{\star *}$ & 4.2 \\
\hline Jul & 2.28 & 1027 & 2.36 & $36^{\star \star}$ & 3.6 \\
\hline Aug & 2.27 & 1017 & 2.34 & $29^{\star \star}$ & 3.0 \\
\hline Sep & 984 & 1007 & 2.32 & $23^{\star \star}$ & 2.3 \\
\hline Oct & 2.03 & 925 & 2.07 & $16^{\star *}$ & 1.7 \\
\hline Nov & 2.03 & 916 & 2.05 & 10 & 1.1 \\
\hline Dec & 2.03 & 907 & 2.04 & 4 & 0.5 \\
\hline Average over 2014 & 934 & 971 & - & $36^{\star *}$ & 3.9 \\
\hline
\end{tabular}

status groups, and the households in the highest category had the steepest rates of decline during the pretax period (fig 2). In the post-tax period both the absolute and the relative differences in predicted post-tax purchases compared with the counterfactual were largest for households of low socioeconomic status, reaching $-35 \mathrm{~mL} /$ capita/day (-17.4\%) by December 2014 and averaging $-19 \mathrm{~mL} /$ capita/day (-9.1\%). Households of middle and high socioeconomic status both reduced purchases of taxed beverages by about $5.5 \%$ to $5.6 \%$ compared with their counterfactuals.

The purchase levels of untaxed beverages before the tax were stable across all socioeconomic status households (fig 3). In the post-tax period, households of middle socioeconomic status showed the greatest increase in purchase of untaxed beverages compared with their counterfactuals, averaging $53 \mathrm{~mL} /$ capita/day (5.9\%), followed by households of low socioeconomic status (19 mL/capita/day; 2.4\%). Households of high socioeconomic status had the smallest increase $(15 \mathrm{~mL} /$ capita/ day; $1.5 \%$ ). However, households of middle and low socioeconomic status both showed larger differences in the earlier months that became smaller over the year, whereas changes among households of high socioeconomic status were less steep over the 12 months, maintaining a difference of 13 to $17 \mathrm{~mL} /$ capita/day $(1.4 \%$ to $1.8 \%$ ) throughout.

\section{Discussion}

This study examines the short term change in purchases of sugar sweetened beverages in stores one year after Mexico implemented a 1 peso per liter excise tax on them. The average volume of taxed beverages purchased monthly was $6 \%$ lower in 2014 compared with expected purchases with the tax absent. Moreover, the reductions accelerated, reaching a $12 \%$ decline by December 2014. The reduction was greatest among households of low socioeconomic status, averaging $-9.1 \%$, and reaching $-17.4 \%$ by December 2014. Purchases of untaxed beverages were $4 \%$ higher than the counterfactual, mainly related to bottled water. Households of middle socioeconomic status increased their purchases the most.

\section{Comparison with other studies}

This study shows the initial changes during the first year of the tax. Economic models of addiction and related behavioral models imply that the long term impact of a price change will be much larger than the short term effect, ${ }^{41}$ but this has been shown only for 

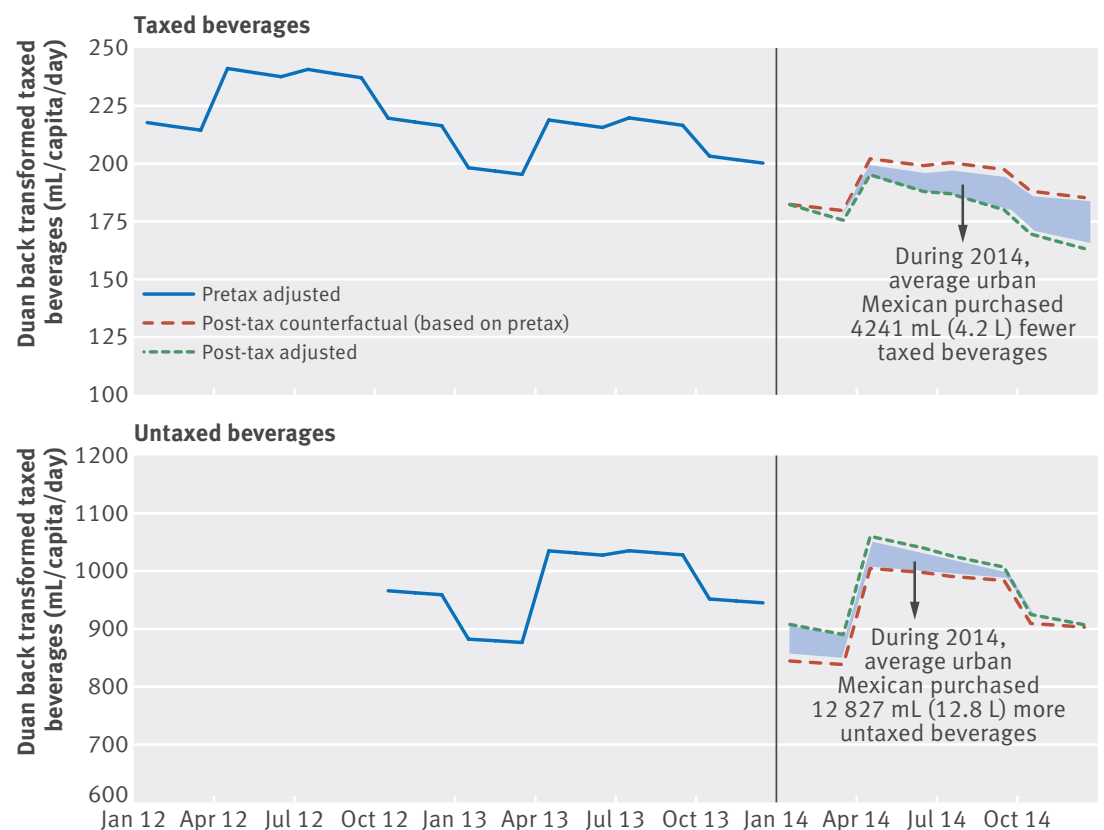

Fig 1 Monthly predicted purchases of beverages comparing counterfactual with post-tax from full sample models (to show seasonal trends in beverage purchases, predictions do not adjust for quarter). Total 2014 changes calculated using only months with significant differences $(P<0.001)$ by taking summation of product of difference for month and number of days in month. Source: authors' own analyses and calculations based on data from Nielsen through its Mexico Consumer Panel Service for food and beverage categories, January 2012 to December 2014 than to the larger packages. ${ }^{26}$ Consequently, consumers may choose to purchase the larger versions, which are cheaper per liter. Future work that incorporates additional data and qualitative monitoring of industry marketing and promotions will allow the study of the longer term effects of the tax on sugar sweetened beverages and the response by industry.

We also found larger reductions in purchases of non-carbonated taxed beverages compared with carbonated taxed beverages. We hypothesize that this could be due to higher prices and high price elasticities of non-carbonated beverages, as shown in earlier work $^{46}$; and consumers shifting to lower priced versions of taxed carbonated beverages given the large variation in prices. ${ }^{26}$ Moreover, the reduction in purchases of taxed sodas and carbonated beverages may be underestimated if purchases of smaller package sizes (which showed a larger increase in price than larger packages after the tax) are not well reported in the data, as these are individual purchases that may be consumed on the go and may be underreported by the key household informant.

Our findings on differential changes by socioeconomic status also shed light on the potential health implications of the tax in Mexico. Over the 12 month taxation period, households of low socioeconomic status reduced their intake of taxed beverages by more than $9 \%$, but, more importantly, by December the decline was $17.1 \%$ more than the counterfactual, with a mean of almost $35 \mathrm{~mL}$. Though prevalence rates for overweight and obesity in the low socioeconomic status group are not significantly higher than those in the higher socioeconomic status groups for all ages, trends in overweight and obesity are increasing faster in children and adolescents in low socioeconomic status groups than in the middle and high socioeconomic status groups. ${ }^{17}$ Taxes on food and beverages have been argued to be regressive as the poor pay a higher proportion of their income. However, results from this study showing a larger reduction in purchases among households of low socioeconomic status suggest that the burden of the tax was lower than it would have been if there was no differential impact by socioeconomic status. Additionally, if the tax revenue is appropriated toward decreasing disparities in health or socioeconomic status, the broader fiscal effects of the tax could arguably be progressive. Although the tax revenue has not been specifically earmarked, the senate made a resolution to use part of the taxes for providing potable water to public schools, particularly in low income areas.

\section{Strengths and limitations of this study}

A major limitation of this work is that causality cannot be established, as other changes are occurring concurrent with the tax, including economic changes, health campaigns about sugar sweetened beverages, and antiobesity programs. We attempted to deal with potential contextual economic factors by controlling for state quarterly unemployment rates and state yearly minimum salaries, but this may have been insufficient. 

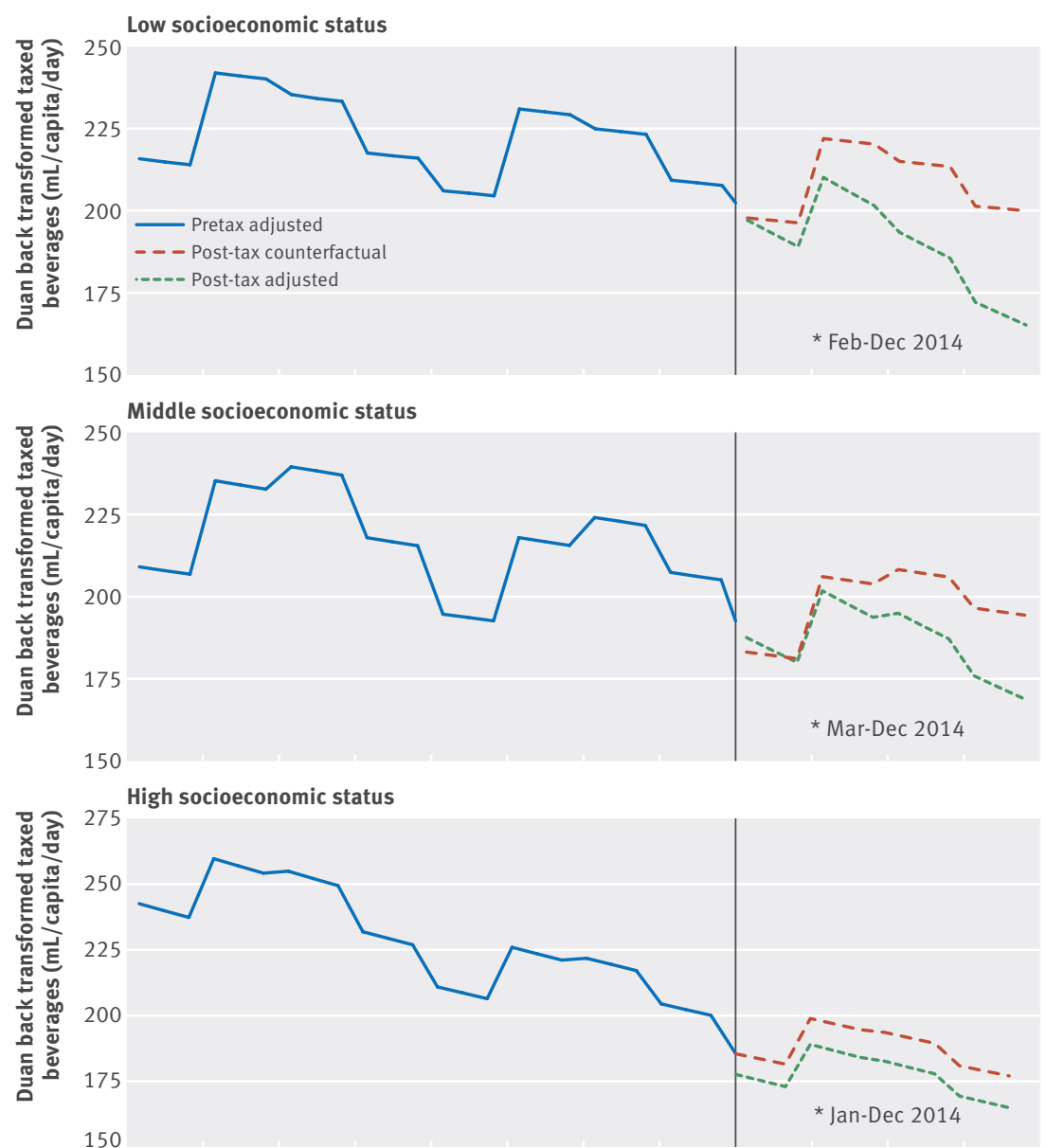

Jan 12 Apr 12 Jul 12 Oct 12 Jan 13 Apr 13 Jul 13 Oct 13 Jan 14 Apr 14 Jul 14 Oct 14

Fig 2 Monthly predicted purchases of taxed beverages comparing counterfactual with post-tax from socioeconomic status stratified models (to show seasonal trends in beverage purchases, predictions do not adjust for quarter). Source: authors' own analyses and calculations based on data from Nielsen through its Mexico Consumer Panel Service for food and beverage categories, January 2012 to December 2014. ${ }^{*} \mathrm{P}<0.001$

The difference in difference approach attempts to take into account any pre-existing (pretax) trends in purchases, but it assumes that these trends would have continued if the tax had not been instituted.

Weaknesses include the incomplete data on dairy beverages before October 2012, which limited the overall analysis for untaxed beverages to a shorter period and likely overestimated the relative increase in purchases of untaxed beverages during the post-tax period. This is not ideal, as a longer pretax period may have allowed findings to be more robust. This is true in general (for all beverages), but we were limited by how far back we were able to obtain the data from Nielsen Consumer Panel Survey, and, regardless, the incomplete data on use of dairy beverages would have persisted.

Also, the data only represent consumers in Mexican cities with more than 50000 residents. Consequently, the sample does not represent a small but important subpopulation living in towns and rural localities with fewer than 50000 people that comprise about $25 \%$ of food and beverage expenditures and around $37 \%$ of the population..$^{31}$ Given that we found a larger reduction in purchases of taxed beverages among households of low socioeconomic status, we hypothesize that reductions among rural households would be greater than those among urban households. However, without actual data, this assumption is purely speculative..

Additionally, we currently do not have data on nutrients for packaged beverages and foods in Mexico, so we cannot quantify any potential changes in calories and other nutrients purchased, and their potential health implications. We also do not have actual data on dietary intake and comparable data on purchases of taxed beverages out of stores. The average increase in purchases of untaxed beverages of $4 \%$ may be underestimated if households shifted to beverages not sold in stores and therefore not reported in the dataset, such as tap water or beverages prepared at home with or without sugar, including aguas frescas (drinks comprising fruits, flowers, cereals, or seeds blended with sugar and water). However, because the beverage tax was structured as an excise tax, these price changes should affect all venues, including fast food outlets using concentrates and syrups and street stalls. Thus our results probably underestimate the total impact, as we did not cover beverages consumed away from home, such as those purchased from street vendors or in restaurants. We are also currently unable to quantify the use of revenues from the tax on sugar sweetened beverages to supply potable water in schools, which could influence the demand for both taxed and untaxed beverages in the longer term.

Furthermore, not only must the effects of the tax be understood but also the effects of the tax on non-essential energy dense foods. On the basis of ENSANUT 2012 data, the two taxes covered approximately 19\% of the daily caloric intake of Mexicans, with 7.5\% coming from taxed beverages. ${ }^{47}$ Since these taxes were implemented concurrently, we cannot determine the independent role of each until changes are made to one of them.

\section{Conclusions and policy implications}

This study documented the change in purchases of beverages after the implementation of a national excise tax on sugar sweetened beverages, and the findings are relevant for policy discussions and decisions. Other than a few business reports on beverage sales for specific companies in Mexico that seem to be in line with what we found, ${ }^{484950}$ no comparable studies have been done to date, as most research on the effects of price changes or taxes on sugar sweetened beverages is derived from model simulations. ${ }^{1}$ France is the only other country to implement a tax on sugar sweetened beverages similar to that of Mexico. ${ }^{51}$ However, France does not have comparable scanned data on household food purchases in relation to its tax, and analyses are limited to sales data (V Requillart, Toulouse School of Economics, personal communication, 2014). In the United States, Berkeley in California instituted a tax on sugar sweetened beverages in March 2015, and initial studies indicate that there is some price pass through, 52 though it is too early to determine how purchases or consumption would be affected and how generalizable these results would be given the limited geographic coverage of the Berkeley tax. The results for Mexico 

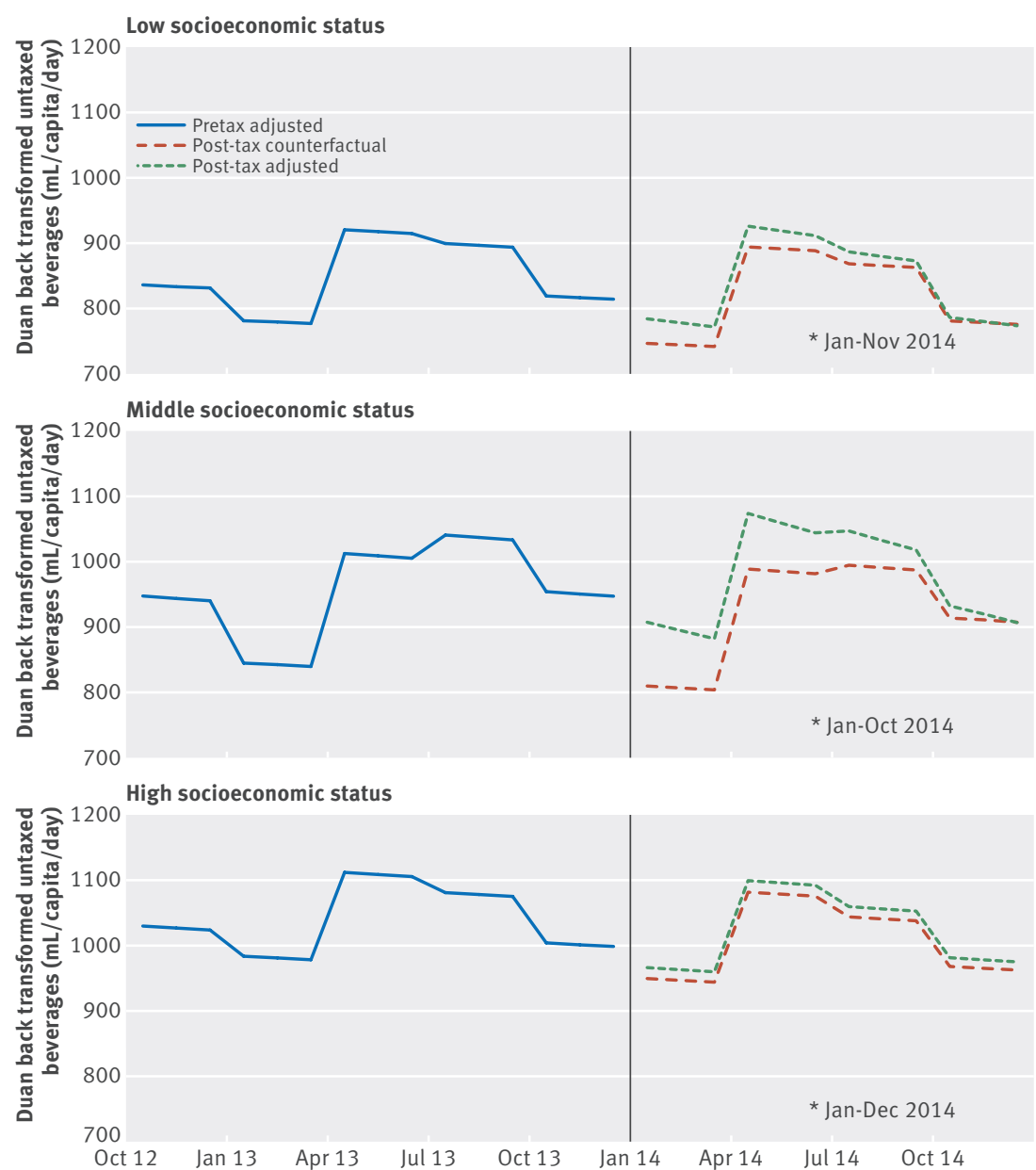

Fig 3 Monthly predicted purchases of untaxed beverages comparing counterfactual with post-tax from socioeconomic status models (to show seasonal trends in beverage purchases, predictions do not adjust for quarter). Based on models using October 2012 to December 2014 data only. Source: authors' own analyses and calculations based on data from Nielsen through its Mexico Consumer Panel Service for food and beverage categories, January 2012 to December 2014. ${ }^{\star} \mathrm{P}<0.001$

show that in the short term the tax on sugar sweetened beverages is generally passed on through prices (the tax passed close to 1 peso/L for carbonated beverages and $<1$ peso/L for non-carbonated beverages in urban areas) ${ }^{2627}$ to consumers, who reduced their purchases of taxed beverages.

These reductions became larger over time, while the purchases of untaxed beverages increased. This short term change is moderate but important, and it will be critical to continue monitoring purchases to note whether the trend continues or stabilizes; consumers substitute cheaper brands or untaxed foods and beverages for the taxed ones, or adjustments occur in the longer term. This will allow for an understanding of the long term effects of taxes on both sugar sweetened beverages and non-essential energy-dense food on purchases, diets, and ultimately health outcomes. In addition, future analysis will look at the distribution of changes in food purchases to determine if the tax on sugar sweetened beverages is more strongly associated with changes among consumers who purchase and consume larger quantities of sugar sweetened beverages.
We thank Donna Miles for data management and programming support; Tania Aburto, Lilia Pedraza, Juan Carlos Salgado, and Emily Ford Yoon for research assistance; Frances L Dancy for administrative assistance; Mauricio Hernandez Avila; and our independent evaluation advisory committee, comprised of: Harold Alderman, Frank Chaloupka, Corinna Hawkes, Shiriki Kumanyika, Gonzalo Hernandez Licona, Luis Rubalcava, Carlos Aguilar Salinas, Sinne Smed, Mary Story, and Walter Willett. We also thank reviewers for their helpful comments. The Nielsen Company is not responsible for and had no role in preparing the results reported in this study.

Contributors: MAC was involved in the literature search, study design, and data analysis and interpretation. BMP was involved in the literature search, study design, and data collection and interpretation. JAR was involved in the literature search, study design, and data interpretation. SWN was involved in the literature search, study design, and data collection, management, analysis, and interpretation. All authors helped to write the manuscript. They had access to the data (including statistical reports and tables) in the study and take responsibility for the integrity of the data and the accuracy of the data analysis. BMP and SWN are guarantors for this study.

Funding: This work was supported by grants from Bloomberg Philanthropies and the Robert Wood Johnson Foundation and by the Instituto Nacional de Salud Pública and the Carolina Population Center. The funders had no role in the study design or the analysis and interpretation of the data. All authors and their institutions reserve intellectual freedom from the funders.

Competing interests: All authors have completed the ICMJE uniform disclosure for at www.icmje.org/coi disclosure.pdf (available on request from the corresponding author) and have declared funding sources, have had no financial relationships with any organizations that might have an interest in the submitted work in the previous three years, and have had no other relationships or activities that could appear to have influenced the submitted work.

Ethical approval: This study (No 14-0176) is exempt from approval by internal review board (reviewed by University of North Carolina at Chapel Hill office of human research ethics).

Data sharing: Owing to the proprietary nature of the main data source used for this analysis, the authors are contractually bound and unable to share the data.

Transparency: The lead authors (BMP and SWN) affirm that the manuscript is an honest, accurate, and transparent account of the study reported; that no important aspects of the study have been selectively omitted; and that any discrepancies from the study as planned (and, if relevant, registered) have been explained.

This is an Open Access article distributed in accordance with the Creative Commons Attribution Non Commercial (CC BY-NC 3.0) license, which permits others to distribute, remix, adapt, build upon this work non-commercially, and license their derivative works on different terms, provided the original work is properly cited and the use is noncommercial. See: http://creativecommons.org/licenses/by-nc/3.0/.

Powell LM, Chriqui JF, Khan T, Wada R, Chaloupka FJ. Assessing the potential effectiveness of food and beverage taxes and subsidies for improving public health: a systematic review of prices, demand and body weight outcomes. Obes Rev 2013;14: 110-28. doi:10.1111/ obr.12002 23174017

2 Andreyeva T, Chaloupka FJ, Brownell KD. Estimating the potential of taxes on sugar-sweetened beverages to reduce consumption and generate revenue. Prev Med 2011;52: 413-6. doi:10.1016/j. ypmed 2011.03 .01321443899

Brownell KD, Farley T, Willett WC. The public health and economic benefits of taxing sugar-sweetened beverages. N EnglJ Med 2009;361:1599-605. doi:10.1056/NEJMhpr0905723 19759377 4 Mytton OT, Clarke D, Rayner M. Taxing unhealthy food and drinks to improve health. BMJ 2012;344: e2931. doi:10.1136/bmj. e2931 22589522

5 Malik VS, Popkin BM, Bray GA, Després JP, Willett WC, Hu FB. Sugarsweetened beverages and risk of metabolic syndrome and type 2 diabetes: a meta-analysis. Diabetes Care 2010;33: 2477-83. doi:10.2337/dc10-1079 20693348

6 Malik VS, Schulze MB, Hu FB. Intake of sugar-sweetened beverages and weight gain: a systematic review. Am J Clin Nutr 2006;84: 274-88. 16895873

Te Morenga L, Mallard S, Mann J. Dietary sugars and body weight: systematic review and meta-analyses of randomised controlled trials and cohort studies. BMJ 2012;346: e7492. doi:10.1136/bmj. e7492 23321486

$8 \quad$ Lesser LI, Ebbeling CB, Goozner M, Wypij D, Ludwig DS. Relationship between funding source and conclusion among nutrition-related scientific articles. PLoS Med 2007;4: e5. doi:10.1371/journal. pmed.0040005 17214504 
9 Wolf A, Bray GA, Popkin BM. A short history of beverages and how our body treats them. Obes Rev 2008;9:151-64. doi:10.1111/i.1467-789x.2007.00389 × 18257753

10 Malik VS, Pan A, Willett WC, Hu FB. Sugar-sweetened beverages and weight gain in children and adults: a systematic review and meta-analysis. Am J Clin Nutr 2013;98: 1084-102. doi:10.3945/ ajcn.113.058362 23966427

11 Ebbeling CB, Feldman HA, Chomitz VR. A randomized trial of sugar-sweetened beverages and adolescent body weight. N EnglJ Med 2012:367: 1407-16. doi:10.1056/NEJMoa1203388 22998339

12 De Ruyter JC, Olthof MR, Seidell JC, Katan MB. A trial of sugar-free or sugar-sweetened beverages and body weight in children. N EnglJ Med 2012;367: 1397-406. doi:10.1056/NEJMoa1203034 22998340

13 Villalpando S, Rodrigo JR. The status of non-transmissible chronic disease in Mexico based on the National Health and Nutrition Survey 2006. Introduction. Salud Publica Mex 2010;52(Suppl 1): S2-3. doi:10.1590/S0036-36342010000700002 20585725

14 Barquera S, Campos-Nonato I, Hernández-Barrera L, Pedroza A, RiveraDommarco JA. Prevalence of obesity in Mexican adults 2000-2012. Salud Publica Mex 2013:55(Suppl 2): S151-60. 24626691

15 Rivera-Dommarco J, Shamah T, Villalpando-Hernández S, eds. Encuesta Nacional de Nutrición 1999. INEGI.Ministry of Health, National Institute of Public Health, 2001.

16 Gutiérrez J, Rivera-Dommarco J, Shamah-Levy T. Encuesta Nacional de Salud y Nutrición 2012. Resultados Nacionales. Instituto Nacional de Salud Pública, 2012

17 Rivera JA, Gonzalez de Cossio T. Nutrición y salud.In: Rolando Cordera CM, ed. Los determinantes sociales de la salud en México. Fondo de Cultura Económica; 2012:269-320.

18 Organization for Economic Cooperation and Development Health at a Glance 2015.Poorkings Institution Press; 2015. www.brookings.edu/ research/books/2015/health-at-a-glance-2015.

19 Institute of Heallth Metrics and Evaluation. Mexico global burden of disease. IHME. 2014 www healthdata org/mexico.

20 Barquera S, Hernandez-Barrera L, Tolentino ML. Energy intake from beverages is increasing among Mexican adolescents and adults. J Nutr 2008;138: 2454-61. doi:10.3945/jn.108.092163 19022972

21 Barquera S, Campirano F, Bonvecchio A, HernándezBarrera L, Rivera JA, Popkin BM. Caloric beverage consumption patterns in Mexican children. Nutr J 2010;9: 47-56. doi:10.1186/1475-2891-9-47 20964842

22 Stern D, Piernas C, Barquera S, Rivera JA, Popkin BM. Caloric beverages were major sources of energy among children and adults in Mexico, 1999-2012. J Nutr 2014;144: 949-56. doi:10.3945/ in.114.190652 24744311

23 Barquera S, Campos I, Rivera JA. Mexico attempts to tackle obesity: the process, results, push backs and future challenges. Obes Rev 2013:14(Suppl 2): 69-78. doi:10.1111/obr.12096 24103026

24 Rivera JA, Muñoz-Hernández O, Rosas-Peralta M, Aguilar-Salinas CA, Popkin BM, Willett WCComité de Expertos para las Recomendaciones. Beverage consumption for a healthy life: recommendations for the Mexican population]. Salud Publica Mex 2008;50: 173-95. doi:10.1590/S0036-36342008000200011 18372998

25 Chamber of Deputies of the Mexican Congress. Ley de Impuesto Especial sobre Producción y Servicios. [Law of special tax on production and services]. 2013. www.diputados.gob.mx/LeyesBiblio/pdf/78_181115.pdf.

26 Colchero MA, Salgado JC, Unar-Munguía M, Molina M, Ng S, RiveraDommarco JA. Changes in prices after an excise tax to sugar sweetened beverages was implemented in Mexico: evidence from urban areas. PLoS One 2015;10: e0144408. doi:10.1371/journal.pone.014440826675166

27 Grogger J. Soda taxes and the prices of sodas and other drinks: evidence from Mexico. Working Paper 21197. NBER, 2015. www.nber. org/papers/w21197.

28 Ng SW, Popkin BM. Monitoring foods and nutrients sold and consumed in the United States: dynamics and challenges. I Acad Nutr Diet 2012;112: 41-45.e4. doi:10.1016/j.jada.2011.09.015 22389873

29 Ng SW, Slining MM, Popkin BM. The Healthy Weight Commitment Foundation pledge: calories sold from U.S. consumer packaged goods, 2007-2012. Am J Prev Med 2014;47: 508-19. doi:10.1016/i. amepre.2014.05.029 25240967

30 Finkelstein EA, Zhen C, Nonnemaker J, Todd JE. Impact of targeted beverage taxes on higher- and lower-income households. Arch Intern Med 2010;170: 2028-34. doi:10.1001/archinternmed.2010.449 21149762

31 Instituto Nacional de Estadística y Geografía. Encuesta Nacional de Ingreso y Gastos de los Hogares. [National Household Income and Expenditure Survey]. 2008, 2010, 1012, 1014. www.inegi.org.mx/est/ contenidos/Proyectos/encuestas/hogares/regulares/enigh.
32 Instituto Nacional de Estadística y Geografía. Encuesta Nacional de Ocupación y Empleo. Indicadores estratégicos. [National Survey of Occupation and Employment: strategic indicators]. 2014. www3. inegi.org.mx/sistemas/temas/default.aspx? s=est $\& \mathrm{c}=25433 \& \mathrm{t}=1$.

33 Comisión Nacional de los Salarios Mínimos. Tabla de Salarios Mínimos Generales y Profesionales por áreas geográficas. [Table of minimum wages: general and professional by geography]. 2014. www.conasami.gob.mx/t_sal_mini_prof.html.

34 Romero-Martínez M, Shamah-Levy T, Franco-Núñez A. Encuesta Nacional de Salud y Nutrición 2012: diseño y cobertura. [National Health and Nutrition Survey 2012: design and coverage]. Salud Publica Mex 2013;55(Suppl 2): S332-40. 24626712

35 StataCorp. Stata statistical software: Release 13. StataCorp, 2014.

36 Athey S, Imbens GW. Identification and inference in nonlinear difference-in-differences models. Econometrica 2006;74: 431-97doi:10.1111/j.1468-0262.2006.00668.x

37 Donald SG, Lang K. Inference with difference-in-differences and other panel data. Rev Econ Stat 2007;89: 221-33 doi:10.1162/ rest.89.2.221.

38 Duan N. Smearing estimate: a nonparametric retransformation method. IAm StatAssoc 1983;78: 605-10doi:10.1080/01621459.1983.10478017.

39 Belotti F, Deb P, Manning WG, Norton EC. twopm: two-part models. Stata / 2015:15:3-20. www.stata-journal.com/article. html?article=st0368

40 Haines P, Guilkey D, Popkin B. Modelling food group decisions as a two-step process. J Agric Econ 1988:70: 543-52doi:10.2307/1241492.

41 Jensen JD, Smed S. The Danish tax on saturated fat-short run effects on consumption, substitution patterns and consumer prices of fats. Food Policy 2013;42:18-31. www.sciencedirect.com/science/article/ pii/S0306919213000705doi:10.1016/j.foodpol.2013.06.004.

42 Becker GS, Murphy KM. A theory of rational addiction. J Polit Econ 1988;96: 675-700. www.jstor.org/stable/1830469doi:10.1086/261558.

43 Grossman M, Chaloupka Fl. The demand for cocaine by young adults: a rational addiction approach. J Health Econ 1998;17: 427-74. doi:10.1016/S0167-6296(97)00046-510180926

44 Gruber J, Koszegi B. Is addiction "rational"? Theory and evidence. QJEcon 2001;116: 1261-303. http://qje.oxfordjournals.org/ content/116/4/1261.abstractdoi:10.1162/003355301753265570.

45 Powell LM, Chaloupka FJ. Food prices and obesity: evidence and policy implications for taxes and subsidies. Milbank Q 2009;87: 229 57. doi:10.1111/j.1468-0009.2009.00554.x 19298422

46 Colchero MA, Salgado JC, Unar-Munguía M, Hernández-Ávila M, RiveraDommarco JA. Price elasticity of the demand for sugar sweetened beverages and soft drinks in Mexico. Econ Hum Biol 2015;19: 129-37. doi:10.1016/j.ehb.2015.08.007 26386463

47 Stern D, Piernas C, Barquera S, Rivera JA, Popkin BM. Caloric beverages were major sources of energy among children and adults in Mexico, 1999-2012. J Nutr 2014;144: 949-56. doi:10.3945/ jn.114.190652 24744311

48 Guthrie A. Mexico soda tax dents coke bottler's sales: Coca-Cola Femsa says Mexican sales volume has fallen more than $5 \%$ this year. Wall Street Journal; 2014. http://online.wsj.com/news/articles/SB10 001424052702303801304579407322914779400

49 Case B. Soft-drink thrist quenched by Pena Nieto tax: corporate Mexico. Bloomberg News. 27 March, 2014. www.bloomberg.com/ news/articles/2014-03-27/ soft-drink-thirst-quenched-by-pena-nieto-tax-corporate-mexico.

50 Gallucci M. As Mexico's sugary drink tax turns 1 year old, US health proponents hope it can sway American voters. International Business Times. 11 January 2015. www.ibtimes.com/ mexicos-sugary-drink-tax-turns-1-year-old-us-health-proponentshope-it-can-sway-1779632.

51 Popkin BM, Hawkes C. The sweetening of the global diet, particularly beverages: patterns, trends and implications for diabetes prevention. Lancet Diabetes Endocrinol 2015; published online 2 December doi:10.1016/S2213-8587(15)00419-2.

52 Falbe J, Rojas N, Grummon AH, Madsen KA. Higher retail prices of sugar-sweetened beverages 3 months after implementation of an excise tax in Berkeley, California. Am J Public Health 2015;105: 2194 201. doi:10.2105/AJPH.2015.302881 26444622

(C) BMJ Publishing Group Ltd 2016

Web extra: Supplementary material 